\title{
UPAYA-UPAYA YANG DILAKUKAN OLEH PAM DESA PAKRAMAN TABOLA DALAM MENINGKATKAN KUALITAS PELAYANAN KEPADA PELANGGAN DAN KESEJAHTERAAN PEGAWAI
}

\author{
Ida Ayu Triska Pradnyani Pidada, Ni Wayan Winiasih, \\ Komang Sudi Armaya, Komang Mirah Andari \\ Jurusan Akuntansi, Universitas Pendidikan Ganesha, Singaraja, Bali, Indonesia
}

\begin{abstract}
Abstrak
Penelitian ini bertujuan untuk mengetahui upaya-upaya yang dilakukan dalam meningkatkan kualitas pelayanan PAM Desa Pakraman Tabola di Kecamatan Sidemen sehingga pelayanan yang didapatkan oleh pelanggan/masyarakat menjadi lebih baik, upaya-upaya yang dilakukan dalam meningkatkan kesejahteraan pengelola dan pengurus PAM Desa Pakraman Tabola di Kecamatan Sidemen sehingga dapat mempengaruhi kualitas pelayanan yang diberikan oleh PAM Desa Pakraman Tabola. Dari hasil penelitian PAM Desa Pakraman Tabola sudah membentuk suatu dana pendidikan dan dana pensiunan karyawan yang masing-masing berjumlah $5 \%$ didapat dari dana PAM Desa Pakraman Tabola yang berjumlah 60\% dari Pembagian Selisih Hasil Usaha Tahun 2016. Dalam hal ini tingkat gaji bagi karyawan PAM Desa Pakraman Tabola sudah sesuai dengan UMR yang berlaku di wilayah Karangasem tahun 2016 yaitu sebesar Rp. 1.895.500. Tidak hanya gaji pokok, karyawan PAM Desa Pakraman Tabola juga mendapatkan uang makan dan uang transport. Dengan hal in dapat meningkatkan kualitas pelayanan dan kesejahteraan pengelola dan pengurus PDAM
\end{abstract}

Kata kunci: Kesejahteraan, Kualitas, Pegawai

\begin{abstract}
This study aims to determine the efforts made in improving the quality of PAM services in the Pakraman Tabola Village in Sidemen District so that the services obtained by the customer / community are better, the efforts made in improving the welfare of the managers and administrators of the Pakraman Tabola PAM Village in the District Sidemen so that it can affect the quality of services provided by PAM Desa Pakraman Tabola. From the research results of the PAM Village Pakraman Tabola has formed an education fund and employee retirement funds, each amounting to 5\% obtained from the PAM fund of the Pakraman Tabola Village, amounting to $60 \%$ of the Distribution of Operating Results in 2016. In this case the salary level for PAM employees Desa Pakraman Tabola is in accordance with the UMR in force in the Karangasem region in 2016 which is Rp. 1,895,500. Not only the basic salary, PAM employees in Desa Pakraman Tabola also get food allowance and transportation money. In this case, it can improve the quality of service and welfare of PDAM managers and managers.
\end{abstract}

\section{Keywords : Welfare, Quality, Employees}

\section{Pendahuluan}

Kecamatan Sidemen merupakan salah satu kecamatan yang memiliki sumber mata air terbaik di kabupaten Karangasem. Kecamatan ini terbagi atas sepuluh desa yaitu Desa Tangkup, Desa Wisma Kerta, Desa Lokasari, Desa Sangkan Gunung, Desa Tri Eka Buana, Desa Kerta Buana, Desa Talibeng, Desa Telaga Tawang, Desa Sidemen, dan Desa Sinduwati. Pada umumnya, pengelolaan air yang dikonsumsi oleh masyarakat dalam menjaga ketersediaan air dilakukan oleh suatu lembaga yang khusus menangani pengelolaan dan pendistribusian air bersih yang disebut dengan Perusahaan Daerah Air Minum (PDAM) yang biasanya ada di daerah namun tidak menutup kemungkinan pengelolaan dan pendistribusian air bersih di suatu daerah tidak menggunakan jasa PDAM, hal ini sesuai dengan otonomi daerah yang ada yaitu, suatu daerah diberikan kebebasan dalam menentukan pilihannya dalam memilih jasa perusahaan pengelola dan pendistribusi air bersih, seperti yang yang ada di Kecamatan Sidemen tidak semua warga desanya 
menggunakan jasa PDAM, akan tetapi dalam pendistribusian dan pengelolaan air bersih di kelola oleh Perusahaan Air Minum Desa (PAM Desa) milik Desa Pakraman Tabola.

Tidak semua desa yang ada di Kecamatan Sidemen menggunakan jasa PAM Desa Pakraman Tabola, hanya beberapa desa seperti Desa Talibeng, Desa Sinduwati, Desa Telaga Tawang, dan Desa Sidemen yang menggunakan jasa PAM Desa Pakraman Tabola untuk memenuhi kebutuhan airnya. Dalam pengelolaan dan pendistribusian air, PAM Desa Pakraman Tabola menggunakan sumber mata air yang ada di daerah Iseh, Umagiang, Buka, Tirta Sari, dan Tebeng. Warga yang mendapat pelayanan air adalah warga yang berada di banjar Kikian, Sindu, Punia, Tengah, Sidekarya, Budamanis, Tabola, Undisan/Lantangkatik, Kebon, Kampung Sindu, Telagatawang, Celetiga, dan Talibeng. Dari sekian banyak banjar yang mendapat pelayanan air tersebut tentu belum bisa mendapatkan debit air sesuai dengan kebutuhan masing-masing warga di banjar tersebut. Seperti misalnya, beberapa tahun yang lalu warga di beberapa banjar tidak mendapatkan pelayanan yang maksimal dari PAM Desa Pakraman Tabola seperti misalnya debit air yang tidak lancar dan air tidak tersedia selama 24 jam per hari. Kondisi ini tentu membuat warga menjadi kurang puas akan pelayanan yang didapatkan dan dalam memenuhi kebutuhan air seharihari warga perlu menyediakan bak-bak penampung air untuk dijadikan persediaan apabila air tiba-tiba macet atau mati. Selain hal tersebut, warga yang tinggal di daerah dataran tinggi sering tidak akan mendapatkan pelayanan dari PAM Desa Pakraman Tabola karena keterbatasan pihak PAM Desa Pakraman Tabola dalam menyediakan pompa yang dapat menyalurkan air hingga ke daerah tersebut, oleh karena itu PAM Desa Pakraman Tabola sangat selektif dalam pemilihan konsumen atau pelanggan. Dalam hal kesejahteraan pihak pengelola PAM Desa Pakraman Tabola belum diperhitungkan karena masih terbatasnya dana untuk anggaran tersebut.

Setelah bergantinya kepengurusan pada prakangge Desa Pakraman Tabola yang juga menyebabkan bergantinya kepengurusan PAM Desa Pakraman Tabola, menimbulkan adanya kemajuan dan perbaikan kualitas pelayanan yang diberikan oleh PAM Desa Pakraman Tabola kepada masyarakat, dimana kualitas pelayanan yang dirasakan oleh warga desa pelanggan PAM Desa Pakraman Tabola sudah membaik mulai dari debit airnya yang sudah lancar sehingga tidak ada lagi warga desa yang kesusahan mendapatkan air, serta kesejahteraan pengurus dan pengelola PAM Desa Pakraman Tabola sudah mulai terjamin dengan adanya program-program yang lebih baik dari sebelumnya, misalnya diadakan pelatihan dan dana pensiun bagi pengelola PAM Desa Pakraman Tabola.

Berdasarkan latar belakang diatas, masalah yang dapat dirumuskan adalah Bagaimana upaya-upaya yang dilakukan dalam meningkatkan kualitas pelayanan PAM Desa Pakraman Tabola di Kecamatan Sidemen sehingga pelayanan yang didapatkan oleh pelanggan/masyarakat menjadi lebih baik, Bagaimana upaya-upaya yang dilakukan dalam meningkatkan kesejahteraan pengelola dan pengurus PAM Desa Pakraman Tabola di Kecamatan Sidemen sehingga dapat mempengaruhi kualitas pelayanan yang diberikan oleh PAM Desa Pakraman Tabola.

\section{Hasil dan Pembahasan}

A. Upaya-upaya yang dilakukan dalam meningkatkan kualitas pelayanan PAM Desa Pakraman Tabola di Kecamatan Sidemen sehingga pelayanan yang didapatkan oleh pelanggan/masyarakat menjadi lebih baik.

Pada awal bulan September tahun 2016 PAM Desa Pakraman Tabola menambah satu buah pompa untuk meningkatkan debit air. Alasan tahun-tahun sebelumnya terjadi kemacetan atau tidak meratanya penyaluran air adalah, karena masih terbatasnya pada satu pompa yang digunakan sehingga penyaluran air menjadi tidak maksimal. Penambahan pompa ini membuktikan bahwa kualitas pelayanan yang didapatkan oleh pelanggan atau masyarakat menjadi lebih baik, karena debit air yang didapatkan sudah lancar dan air bisa mengalir selama 24 jam.

Pada teoriBalanced Scorecard yang merupakan suatu metode pengukuran kinerja yang didalamnya ada keseimbangan antara keuangan dan non keuangan untuk mengarahkan kinerja perusahaan terhadap keberhasilan. Balanced Scorecard dapat 
menjelaskan lebih lanjut tentang pencapaian visi yang berperan di dalam mewujudkan pertambahan kekayaan tersebut (Mulyadi dan Johny Setyawan, 2000) seperti peningkatan konsumen yang puas sehingga laba dapat meningkat. Dalam hal ini peningkatan kepuasan konsumen padaPAM Desa Pakraman Tabola dapat dilihat dari meningkatnya laba setelah di tambahnya satu buah pompa yang memaksimalkan dalam pendistribusian air pada bulan Oktober sampai dengan Nopember tahun 2016 yaitu sebesar Rp. 9.592.386. Namun demikian, PAM Desa Pakraman Tabola masih merencanakan target yang akan dilakukan untuk lebih meningkatkan laba sehingga PAM Desa Pakraman Tabola dapat lebih berkembang dan lebih maju lagi.

Dengan semakin baiknya pelayanan yang diberikan oleh PAM Desa Pakraman Tabola kepada para pelanggannya menyebabkan peningkatan pelanggan baru sekitar 30 sampai dengan 45 KK (Kepala Keluarga). Dalam hal ini, PAM Desa Pakraman Tabola sangat selektif dalam memilih pelanggan atau konsumen, seperti misalnya bagi warga yang bertempat tinggal di daerah dataran tinggi akan sulit mendapatkan air sehingga mereka tidak akan mendapatkan pelayanan dari PAM Desa Pakraman Tabola karena meskipun sudah menambah 1 buah pompa baru, air masih belum dapat menjangkau daerah yang terlalu tinggi. Potensi wilayah kerja PAM Desa Pakraman Tabola diutamakan di wilayah Desa Pakraman Tabola, dan desa adat atau banjar diluar Desa Pakraman Tabola seperti Banjar Celetiga dan Banjar Talibeng. Untuk penambahan pompa tersebut, PAM Desa Pakraman Tabola mendapatkan dana dari pinjaman dan dana sendiri milik PAM Desa Pakraman Tabola. Akibat dari penambahan pompa tersebut terjadi penambahan biaya dan utang yang harus dikeluarkan oleh PAM Desa Pakraman Tabola.

Selain penambahan pompa baru, PAM Desa Pakraman Tabola juga memperbaiki pipa-pipa saluran air yang digunakan untuk menyalurkan air ke pelanggan. Tidak lancarnya penyaluran air ke pelanggan dapat juga disebabkan oleh bocornya pipa yang digunakan untuk menyalurkan air. Seperti yang terjadi beberapa waktu yang lalu, terdapat kebocoran pipa di daerah Desa Sinduwati yang menyebabkan air terbuang di daerah sekitar kebocoran pipa tersebut. Pada saat itu penanganan cenderung lambat dilakukan, sehingga menyebabkan air mati hingga berhari-hari di masing-masing rumah pelanggan.

Salah satu penyebab masyarakat atau warga yang menjadi pelanggan PAM Desa Pakraman Tabola enggan untuk membayar air adalah akibat seringnya air mati. Namun, setelah terjadi perbaikan di segala aspek yang dilakukan oleh PAM Desa Pakraman Tabola membuat masyarakat atau pelanggan menjadi sadar akan kewajibannya dan hal ini terbukti dari adanya penurunan pendapatan denda dari bulan Oktober sampai dengan Nopember tahun 2016 sebesar Rp.140.000, dan terjadi peningkatan pendapatan dari pemakaian air oleh pelanggan dari bulan Oktober sampai dengan Nopember tahun 2016 sebesar Rp.1.754.850.

Dalam pemanfaatan sumber mata air, PAM Desa Pakraman Tabola menggunakan sumber mata air yang ada di masing-masing desa agar pemanfaatannya dapat semaksimal mungkin untuk memenuhi kebutuhan pelanggan. Seperti sumbermata air yang ada di Iseh, Umagiang, Buka, dan Tirta Sari yang berada di wilayah Desa Sinduwati digunakan untuk jalur pendistribusian ke Banjar Kikian, Banjar Sindu, Banjar Punia, Banjar Tengah, Banjar Sidekarya, Banjar Budamanis, Banjar Tabola, Banjar Undisan/Lantangkatik, Banjar Kebon, dan Kampung Sindu. Serta sumber mata air di Tebeng yang ada di wilayah Banjar Lantangkatik, Desa Sidemen, didistribusikan untuk jalur Banjar Telagatawang, Banjar Celetiga, dan Banjar Talibeng. Sumber mata air tersebut tidak hanya dimanfaatkan oleh pihak PAM Desa Pakraman Tabola untuk kebutuhan pelanggan PAM Desa Pakraman Tabola saja, akan tetapi masyarakat yang tidak menjadi pelanggan PAM Desa Pakraman Tabola juga ikut memanfaatkan sumber mata air tersebut dengan cara air tidak langsung disalurkan ke rumah-rumah melainkan digunakan hanya disekitar sumber mata air, seperti misalnya untuk pengairan sawah dan lain sebagainya.

Untuk menunjukkan rasa tanggung jawab kepada Tuhan Yang Maha Esa pihak PAM Desa Pakraman Tabola rutin melakukan persembahan upacara ke pura-pura yang ada di masing-masing sumber mata air. Penulis melakuan wawancara dengan pemimpin PAM Desa Pakraman Tabola yaitu bapak I Gusti Ngurah Artana yang menyatakan bahwa : 
"Untuk upacara piodalan dipusatkan pada satu pura yang ada di Kikian, Desa Sinduwati. Selain itu, dana pembagian selisih hasil usaha pihak PAM Desa Pakraman Tabola juga di sumbangkan ke pura-pura kahyangan dan pura dalem".

PAM Desa Pakraman Tabola dalam hal ini merupakan perusahaan yang bergerak di bidang jasa harus mampu memberikan kualitas pelayanan yang baik. Kualitas memberikan pencitraan bagi perusahaan kepada pelanggan, dilihat dari sejauh mana ikatan yang terjalin antara perusahaan dengan pelanggan. Pelanggan merupakan pengguna jasa perusahaan yang nantinya akan menentukan keberlangsungan perusahaan. Kualitas pelayanan merupakan suatu perbedaan seberapa jauh kenyataan dan harapan yang diterima oleh pelanggan, penyajian produk atau jasa sesuai dengan ukuran yang berlaku di tempat produk tersebut diadakan.

\section{B. Upaya-upaya yang dilakukan dalam meningkatkan kesejahteraan pengelola dan pengurus PAM Desa Pakraman Tabola di Kecamatan Sidemen sehingga dapat mempengaruhi kualitas pelayanan yang diberikan oleh PAM Desa Pakraman Tabola.}

Perusahaan Air Minum (PAM) Desa Pakraman Tabola berdiri pada tahun 1980 dan beberapa tahun yang lalu sempat terjadi pergantian atau penyerahan kembali aset milik Desa Pakraman Tabola berupa sarana dan prasarana jaringan instalasi air minum beserta pengelolaannya oleh pihak PDAM Karangasem yang dulunya pernah diserahkan oleh Prakangge Desa.Hal yang menyebabkan terjadinya penyerahan kembali aset tersebut adalah adanya tuntutan warga Desa Pakraman Tabola mengenai kualitas pelayanan PDAM Karangasem yang dirasa kurang optimal pada saat itu. Sehubungan dengan tuntutan warga Desa Pakraman Tabola tersebut, Bupati Karangasem pada saat itu akhirnya mengeluarkan keputusan yang tertuang dalam Berita Acara Nomor : 901/120/PDAM.

Pada tanggal 5 September 2014 PAM Desa Pakraman Tabola melaksanakan pergantian pengurus, dimana menempatkan I Gusti Ngurah Artana sebagai pemimpinPAM Desa Pakraman Tabola. Jumlah pegawai terdiri dari empat orang dan satu orang tenaga kerja/waker. Dengan jumlah pegawai demikian, PAM Desa Pakraman Tabola harus melayani 1449 orang pelanggan yang tersebar di Kecamatan Sidemen. Pergantian kepengurusan ini menimbulkan beberapa perubahan yang tentunya diharapkan akan membawa PAM Desa Pakraman Tabola menjadi lebih baik, baik dari segi pelayanan dan manajemennya.

Kebijaksanaan mengenai kesejahteraan pegawai kiranya tidak akan sulit membayangkan bahwa apabila masing-masing manajer diberi wewenang untuk menentukan sendiri kebijaksanaan tentang jenis dan jumlah dana serta fasilitas kerja yang akan diberikan kepada para pekerja dalam satuan kerja masing-masing, akibatnya akan dapat terlihat pada peningkatan kesejahteraan pegawai yang beraneka ragam dalam organisasi yang sama. Hal demikian akan berakibat bukan hanya pada beban biaya yang sangat besar yang harus dipikul oleh organisasi akan tetapi juga kemungkinan besar akan menggambarkan situasi ketidakadilan. Untuk menghindari situasi yang tidak menguntungkan manajemen puncak biasanya akan memberikan wewenang fungsional kepada manajer sumber daya manusia untuk memutuskannya dan para manajer lini tidak lagi mempunyai diskresi melainkan tinggal melaksanakannya saja.

Dilihat dari bentuk aktivitasnya, manajemen personalia memiliki obyek studi tentang pegawai pada suatu organisasi. (Ambar dan Rosidah, 2003) menurut Taylor ada lima langkah yang sebaiknya ditempuh guna meningkatkan produktivitas perusahaan, yaitu; seleksi orang, menemukan metode kerja yang paling baik, merancang sarana kerja yang cocok serta memanfaatkannya, melatih dan memotivasi karyawan. Dalam hal ini PAM Desa Pakraman Tabola sudah merencanakan berbagai program pendidikan seperti misalnya akan mengikutsertakan pegawai dalam kegiatan-kegiatan seminar, serta mengadakan pelatihanpelatihan untuk mengembangkan kemampuan dan pengetahuan pegawai sehingga nantinya dapat bekerja dengan kualitas pelayanan yang diberikan dapat maksimal. 
Pelatihan dan pengembangan merupakan tanggung jawab bersama dan utamanya manajemen puncak (pimpinan) serta mendapat dukungan dari berbagai pihak. Pimpinan mempunyai tanggung jawab atas kebijakan-kebijakan umum dan prosedur yang dibutuhkan untuk menerapkan proram pelatihan dan pengembangan. Untuk itu komitmen pimpinan sangat penting agar berlangsung secara efektif, baik dari perencanaan, proses serta tujuan dari pelatihan dan pengembangan. Adapun tujuan pelatihan dan pengembangan menurut Henry Simamora, (Ambar dan Rosidah, 2003) yaitu:

a. Memperbaiki kinerja, memutakhirkan keahlian para karyawan sejalan dengan kemajuan teknologi.

b. Mengurangi waktu belajar bagi karyawan baru supaya, menjadi kompeten dalam pegawai.

c. Membantu memecahkan persoalan operasional.

d. Mempersiapkan karyawan untuk promosi.

e. Memenuhi kebutuhan-kebutuhan pertumbuhan pribadi.

Berdasarkan hasil penelitian Elton Mayo (1880-1949) dalam penelitiannya yang dikenal dengan nama Hawthorne Experiment, menyimpulkan bahwa orang dapat mencapai produktivitas tinggi bila menyadari bahwa dirinya memperoleh pengakuan dan penghargaan, dan para pegawai akan mengembangkan norma-norma resmi. Hasil penelitian ini ternyata mendapatkan dukungan dari Mary Parker Follet (1868-1933) yang meyakini bahwa segala masalah manajemen pada hakekatnya merupakan masalah hubungan antar manusia, sedangkan manusia itu sendiri memiliki sifat konstruktif dan kooperatif (Ambar dan Rosidah, 2003).

Selanjutnya yaitu, PAM Desa Pakraman Tabola juga akan melaksanakan program pensiun bagi para karyawannya. Pemberian dana pensiun bagi karyawan PAM Desa Pakraman Tabola ini rencananya akan dilaksanakan bagi karyawan yang telah berumur kurang lebih 55 tahun sebagai tanda rasa terimakasih pihak PAM Desa Pakraman Tabola sehingga nantinya dana tersebut dapat dimanfaatkan meskipun sudah selesai bekerja di PAM Desa Pakraman Tabola. Pemberian dana pensiun kepada karyawan bukan saja hanya memberikan kepastian pengasilan di masa depan, tetapi juga ikut memberikan motivasi bagi para karyawannya untuk lebih giat bekerja. Penulis juga melakukan wawancara dengan salah satu pegawai diPAM Desa Pakraman Tabola yaitu I Dewa Ayu Arini yang menyatakan bahwa:

"Dengan adanya program-program tersebut, setidaknya karyawan di PAM Desa Pakraman Tabola akan merasa sedikit terbantu kesejahteraannya dan lebih semangat untuk melakukan pekerjaan."

Dengan memberikan program jasa pensiun para karyawan merasa aman, terutama bagi mereka yang menganggap pada usia pensiun sudah tidak produktif lagi. Sedangkan bagi sebagian masyarakat yang merasa masih produktif juga akan memberikan motivasi bahwa jasa-jasa mereka masih dihargai oleh perusahaannya.

Untuk merealisasikan rencana tersebut, PAM Desa Pakraman Tabola sudah membentuk suatu dana pendidikan dan dana pensiunan karyawan yang masing-masing berjumlah 5\% didapat dari dana PAM Desa Pakraman Tabola yang berjumlah $60 \%$ dari Pembagian Selisih Hasil Usaha Tahun 2016. Jika pada umumnya, dana pensiun dikelola oleh suatu lembaga dan memungut dana dari pendapatan para karyawan suatu perusahaan kemudian membayarkan kembali dana tersebut dalam bentuk pensiun setelah jangka waktu tertentu sesuai dengan perjanjian antara kedua belah pihak. Maka seperti yang sudah dijelaskan bahwa dana pensiunan karyawan PAM Desa Pakraman Tabola berjumlah $5 \%$ didapat dari dana PAM Desa Pakraman Tabola yang berjumlah 60\% dari Pembagian Selisih Hasil Usaha Tahun 2016.

Program kompensasi penting bagi organisasi karena mencerminkan upaya organisasi untuk mempertahankan sumber daya manusia sebagai komponen utama, dan merupakan komponen biaya yang paling penting. Kompensasi adalah segala sesuatu yang diterima oleh pegawai sebagai balas jasa (kontra prestasi) atas kerja mereka. Kompensasi ada dua macam yaitu langsung dang tidak langsung. Secara definitif kompensasi langsung adalah upah dasar/sistem gaji ditambah bayaran yang berdasarkan penampilan atau prestasi. 
Kompensasi tidak langsung adalah kategori umum tunjangan karyawan, program proteksi yang diamanatkan, asuransi kesehatan, upah waktu tidak bekerja, dan bermacam-macam tunjangan lainnya (Ambar dan Rosidah, 2003).

Dalam hal ini tingkat gaji bagi karyawan PAM Desa Pakraman Tabola sudah sesuai dengan UMR yang berlaku di wilayah Karangasem tahun 2016 yaitu sebesar Rp. 1.895.500. Tidak hanya gaji pokok, karyawan PAM Desa Pakraman Tabola juga mendapatkan uang makan dan uang transport. Selain gaji dan pensiun,dalam hal jaminan keselamatan kerja, asuransi, atau jaminan kesehatan PAM Desa Pakraman Tabola belum bisa merencanakan program-program tersebut.

Berkaitan dengan perubahan status PAM Desa Pakraman Tabola yang dulunya dikelola oleh PDAM Karangasem, yaitu perusahaan pemberi layanan jasa bagi masyarakat di desa-desa yang ada di Kecamatan Sidemen mengharuskan PAM Desa Pakraman Tabola untuk berbenah diri baik dari segi administrasi maupun keuangannya. Karena aspek tersebut tentu saja mengalami perubahan seiring dengan perubahan status tersebut. Pemberian gaji karyawan sesuai UMR yang berlaku, pemberian pelatihan dan pengembangan bagi karyawan, serta rencana pemberian pensiun bagi karyawan diharapkan dapat berdampak positif bagi peningkatan layanan yang diberikan kepada pelanggan atau konsumen yang ada di Kecamatan Sidemen sehingga sumber mata air yang ada di beberapa desa di Kecamatan Sidemen yang pada dasarnya adalah milik masyarakat Kecamatan Sidemen dapat dimanfaatkan dengan baik demi keberlangsungan dan kesejahteraan masyarakat Kecamatan Sidemen itu sendiri.

Rencana anggaran merupakan salah satu faktor yang menentukan keberlanjutan program kegiatan yang dilaksanakan oleh PAM Desa Pakraman Tabola. Penganggaran merupakan hasil kerja (output) terutama berupa taksiran-taksiran tentang sesuatu yang akan terjadi dan yang akan dilaksanakan diwaktu yang akan datang. Menurut Sukarno (2002:172) tujuan penganggaran adalah sebagai berikut :

a. Untuk menyatakan harapan/sasaran perusahaan secara jelas dan formal, sehingga bisa menghindari kerancuan dan memberikan arah terhadap apa yang hendak dicapai manajemen.

b. Untuk mengomunikasikan harapan manajemen kepada pihak-pihak terkait sehingga anggaran dimengerti, didukung dan dilaksanakan.

c. Untuk menyediakan rencana terinci mengenai aktivitas dengan maksud mengurangi ketidakpastian dan memberikan pengarahan yang jelas bagi individu dan kelompok dalam upaya mencapai tujuan perusahaan.

d. Untuk mengkoordinasikan cara/metode yang akan ditempuh dalam rangka memaksimalkan sumber daya.

e. Untuk menyediakan alat pengukur dan mengendalikan kinerja individu dan kelompok, serta menyediakan informasi yang mendasari perlu tidaknya tindakan koreksi.

Pada dasarnya yang berwenang dan bertanggung jawab atas penyusunan anggaran serta pelaksanaan kegiatan anggaran adalah pimpinan tertinggi perusahaan. Namun demikian, tugas menyiapkan dan menyusun anggaran serta kegiatan anggaran tersebut tidak harus ditangani sendiri oleh pimpinan tertinggi perusahaan, melainkan dapat didelegasikan kepada pihak lain di perusahaan. Dalam hal ini perencanaan anggaran pada PAM Desa Pakraman Tabola dapat dilihat dalam tabel berikut:

Tabel 1.1 Rencana Anggaran PAM Desa Pakraman Tabola tahun 2016 (dalam rupiah)

\begin{tabular}{|l|l|c|r|}
\hline No & PAM Desa Pakraman Tabola & $\mathbf{1 4 1 . 9 7 4 . 1 3 3}$ & \\
\hline 1 & Cadangan & $30 \%$ & 42.592 .240 \\
\hline 2 & Dana Pengurus & $7 \%$ & 9.938 .189 \\
\hline 3 & Dana Pengelola & $10 \%$ & 14.197 .413 \\
\hline 4 & Dana ke Pura-pura Kahyangan & $15 \%$ & 21.296 .120 \\
\hline 5 & Dana ke Pura Dalem & $12 \%$ & 17.036 .896 \\
\hline 6 & $\begin{array}{l}\text { Dana ke Banjar-banjar (sedesa } \\
\text { Pakraman Tabola) }\end{array}$ & $11 \%$ & 15.617 .155 \\
\hline 7 & Dana Pembangunan dan Sosial & $5 \%$ & 7.098 .707 \\
\hline
\end{tabular}




\begin{tabular}{|l|l|c|l|}
\hline 8 & Dana Pendidikan & $5 \%$ & 7.098 .707 \\
\hline 9 & Dana Pensiunan Karyawan & $5 \%$ & 7.098 .707 \\
\hline \multicolumn{2}{|c|}{ Total } & $\mathbf{1 0 0 \%}$ & $\mathbf{1 4 1 . 9 7 4 . 1 3 3}$ \\
\hline
\end{tabular}

Sumber: Catatan Atas Laporan Keuangan PAM Desa Pakraman Tabola tahun 2016

Pada tabel tersebut dapat dijelaskan bahwa, nilai sebesar 141.974.133 didapatkan dari laba tahun berjalan bulan Januari s.d Nopember tahun 2016 dikalikan dengan $60 \%$ (60\% merupakan prosentase Pembagian Hasil Usaha tahun 2016 bagi PAM Desa Pakraman Tabola). Pembagian Hasil Usaha tersebut lalu dianggarkan sedemikian rupa agar dana yang dimiliki dapat berjalan dengan baik demi pembangunan ke arah yang lebih baik untuk kesejahteraan PAM Desa Pakraman Tabola serta seluruh pelanggannya yang secara tidak langsung juga berdampak bagi masyarakat di desa-desa Kecamatan Sidemen.

\section{Simpulan Dan Saran}

Pada awal bulan September tahun 2016 PAM Desa Pakraman Tabola menambah satu buah pompa untuk meningkatkan debit air. Dengan semakin baiknya pelayanan yang diberikan oleh PAM Desa Pakraman Tabola kepada para pelanggannya menyebabkan peningkatan pelanggan baru sekitar 30 sampai dengan 45 KK (Kepala Keluarga). Akan tetapi, meskipun sudah menambah 1 pompa air baru, air masih belum dapat menjangkau ketempat yang lebih tinggi. Selain penambahan pompa baru, PAM Desa Pakraman Tabola juga memperbaiki pipa-pipa saluran air yang digunakan untuk menyalurkan air ke pelanggan. Dalam pemanfaatan sumber mata air, PAM Desa Pakraman Tabola menggunakan sumber mata air yang ada di masing-masing desa agar pemanfaatannya dapat semaksimal mungkin untuk memenuhi kebutuhan pelanggan. Untuk menunjukkan rasa tanggung jawab kepada Tuhan Yang Maha Esa pihak PAM Desa Pakraman Tabola rutin melakukan persembahan upacara ke pura-pura yang ada di masing-masing sumber mata air. Namun untuk upacara piodalan dipusatkan di satu pura yang ada di Desa Sinduwati,Kikian.

Pada tanggal 5 September 2014 PAM Desa Pakraman Tabola melaksanakan pergantian pengurus, dimana menempatkan I Gusti Ngurah Artana sebagai pemimpinPAM Desa Pakraman Tabola. Jumlah pegawai terdiri dari empat orang dan satu orang tenaga kerja/waker.Pergantian kepengurusan ini menimbulkan beberapa perubahan yang tentunya diharapkan akan membawa PAM Desa Pakraman Tabola menjadi lebih baik, baik dari segi pelayanan dan manajemennya. PAM Desa Pakraman Tabola sudah membentuk suatu dana pendidikan dan dana pensiunan karyawan yang masing-masing berjumlah $5 \%$ didapat dari dana PAM Desa Pakraman Tabola yang berjumlah 60\% dari Pembagian Selisih Hasil Usaha Tahun 2016. Dalam hal ini tingkat gaji bagi karyawan PAM Desa Pakraman Tabola sudah sesuai dengan UMR yang berlaku di wilayah Karangasem tahun 2016 yaitu sebesar Rp. 1.895.500. Tidak hanya gaji pokok, karyawan PAM Desa Pakraman Tabola juga mendapatkan uang makan dan uang transport. Ada pun saran dari kesimpulan tersebut: Bagi penulis, Penulis masih menyadari bahwa penelitian ini masih jauh dari kesempurnaan, kedepannya penulis berharap agar diberikan kritik dan saran yang membangun agar lebih memperhatikan dalam menulis penelitian selanjutnya serta Bagi perusahaan, Programprogram baru yang sudah berhasil dilaksanakan oleh PAM Desa Pakraman Tabola telah membawa perubahan yang cukup signifikan yang dirasakan oleh pelanggan sehingga kepuasan pelanggan akan menjadi kebanggaan tersendiri bagi pengelola PAM Desa Pakraman Tabola yang dalam hal ini merupakan pelayan bagi masyarakat yang secara tulus mengabdi. Akan tetapi sebagai perusahaan yang melayani masyarakat, perlu diadakan evaluasi agar perusahaan bisa memenuhi harapan pelanggan kedepannya. Untuk meningkatkan kualitas pelayanan PAM Desa Pakraman Tabola perlu memperhatikan apa yang menjadi harapan pelanggan, seperti misalnya masyarakat di daerah dataran tinggi kedepannya diharapkan akan mendapatkan pelayanan dari PAM Desa Pakraman Tabola dengan menambah daya pompa sehingga air dapat mencapai lokasi tersebut. Dalam kesejahteraan karyawan, selain gaji dan pensiun,dalam hal jaminan keselamatan kerja, 
asuransi, atau jaminan kesehatan PAM Desa Pakraman Tabola belum bisa merencanakan program-program tersebut. Sehingga akan lebih baik lagi jika program asuransi tersebut bisa dilaksanakan demi meningkatkan kesejahteraan karyawan yang nantinya juga akan berdampak pada kualitas pelayanan yang diberikan oleh karyawan kepada pelanggan.

\section{DAFTAR PUSTAKA}

Kasmir, Dr. 2012. Bank dan Lembaga Keuangan Lainnya. Jakarta:PT. RAJAGRAFINDO PERSADA.

Niswatin dan Nilawaty Yusuf. 2015. Prioritas Program Kerja Sebagai Dasar Penyusunan Rencana Bisnis Anggaran (RBA) Unit Kerja Program Studi S1 Akuntansi. Jurnal IImiah Akuntansi \& Humaniora, 4: 1562-1585.

Sulistiyani, Ambar Teguh dan Rosidah. 2003. Manajemen Sumber Daya Manusia; Konsep, Teori dan Pengembangan dalam Konteks Organisasi Publik. Yogyakarta:Graha Ilmu. 